Original Research Paper

\title{
Job Satisfaction and Family Functioning of Dual-Earner Commuter Family in Malaysia
}

\author{
Farah Syuhada Pai and Zarinah Arshat \\ Department of Human Development and Family Studies, Faculty of Human Ecology, Universiti Putra Malaysia, Malaysia
}

\author{
Article history \\ Received: 22-07-2019 \\ Revised: 05-11-2019 \\ Accepted: 15-01-2020 \\ Corresponding Author: \\ Zarinah Arshat \\ Department of Human \\ Development and Family \\ Studies, Faculty of Human \\ Ecology, Universiti Putra \\ Malaysia, Malaysia. \\ Email: zarinah_upm@upm.edu.my
}

\begin{abstract}
The aim of the present study is to determine the relationship between job satisfaction and family functioning of dual-earner commuter family in Malaysia. More over, the investigation of the differences on job satisfaction and family functioning based on gender is also being analyzed. A total sample of 180 respondents were analyzed with correlation and t-test analysis. Results showed that respondents with high level of job satisfaction were more likely to experience high level of family functioning. Besides, results also showed that there were no significant differences between husband and wife in job satisfaction and family functioning. These finding suggest that information in this present study is useful to dual-earner commuter family and others. The limitations of the study were also discussed in this study.
\end{abstract}

Keywords: Job Satisfaction, Family Functioning, Dual-Earner Commuter Family

\section{Introduction}

In recent years, there are increasing number of job relocation all over the world. More over, increasing number of women involve in the labour force in $21 \mathrm{st}$ century become a most of major trends in Malaysia which lead to increasing number of dual-earner commuter families. According to Rabe (2001), dualearner commuter families had been defined as two people who are married, but has seperated residence for at least the greater part of the week (i.e., more than fours days per weeks) due to places of work which are geographically far from each other. Usually, the choice of commuter partnership can be motivated by a partners career commitment and particularly in case of dualearner couple's (Van der Klis, 2008). There are some factors that would encourage couples to consider to be a commuter family's which are: (1) Financials need or crisis, (2) professional imperative and (3) recognicion of potential oppurtinity (Rotter et al., 1998; Glotzer and Federlein, 2007). To that end, job satisfaction and family functioning can play an important role towards commuter families in Malaysia.

Alegre et al. (2016) stated that job satisfaction as an emotion which involves person's overall evaluation towards their work environment. Most of research had shown that intrinsic and extrinsic factors provide a stronger effects towards job satisfaction such as interest, challenge and pay given (Ganzach and Fried, 2012; Gagne and Deci, 2005). To put it another way, company's support towards employee work-family balance (Alegre et al., 2016) is one of the factors that will foster a high level of job satisfaction although in the presence of low level of work-family balance. Beside that, individuals with strong adaptability resources may consider career challenges as opportunities rather than threat by increasing their developmental skill and positive emotion and also will lead to higher job satisfaction (Fiori et al., 2015). Moreover, there were two components in job satisfaction such as intrinsic satisfaction (interesting work and job feedback) and extrinsic satisfaction (high income level and job security). Again, past study by Fiori et al. (2015) has revealed highly intrinsic individuals feel more confidence to overcome any problems related to their job, lower negative emotions and work stress which leading to increases in job satisfaction. Meanwhile, worker with highly extrinsic satisfaction particularly motivated by employment opportunities and financial rewards which foster a good attendance and more likely to continued work.

Where as, family functioning had been defined as a delicate balance between family cohesion or closeness 
and family adaptability or the capacity to be flexible and adapt to challenges and changes both within the family and within the environment (Olson, 1993). There are two main dimensions in family functioning systems which are family cohesion and adaptability. In the Circumplex model proposed by Olson (1993) found that cohesion can be defined as emotional bonding exist in family members towards each other, whereas adaptability is marital or family ability to change its power, role relationships, rule to responds to a situational and developmental stress. More over, in the Circumplex model there are specific concept were used to measure the dimension of cohesion such as emotional bonding, boundaries, time, space, friends, decision making, interest, recreation and coalition, while adaptability consists of family power (assertiveness, control, discipline), negotiation style, role and rule of the relationships. Furthermore, according to Zubrick et al. (2000), work is one of the major barrier to a quality of time available in the family. This is because amount and quality time are really important for family functioning. In supporting previous notion, Zubrick et al. (2000) in their study found that time can act as a resources for functioning of the family by each of the family members make available time for one another. Particularly, higher level of work hour and emotional exhaustion in the work setting will not only give a direct impact towards the employee but also reduce the family functioning (Rupert et al., 2013) in the commuter family due to limited time and energy level to spend with family members.

Based on the previous research and model above, the present research thus examine the relationship betweeen job satisfaction and family functioning in dual-earner commuter families in Malaysia. This curent study also determine the differences on job satisfaction and family functioning based on gender.

\section{Methodology}

\section{Participants and Procedure}

A total of 180 participants in Malaysia were recruited in this study. The criteria of the participants involved in this study were husband and wife in commuter family, came from dual-earner partnerships, living separately in different residence and with or without a child age range below 18 years old. Technique of sampling used in this study was purposive sampling. According to Van der Klis (2008), a benefit of purposive sampling is that it helps to study a specific part of the population and to select respondent based on the specific similarities and differences, but it also creates artificial boundaries between categories of people who are supposed to be similar in the life style. The structured self-administrative questionnaire was distributed to the participants.

\section{Measures}

Social-Demographics information was collected from the couples of dual-earner commuter in this study. Respondents were asked to indicate their age, years of marriage, occupation sector, year of education and total monthly income. In the mean time, couples were also responded to job satisfaction and family functioning scale.

Job Satisfaction was measured by the Minnesota Satisfaction Questionnaire Short Form (MSQ-SF) (Weiss et al., 1967) which consists of two subscales: Intrinsic job satisfaction and extrinsic job satisfaction. Example of the item in intrinsic job satisfaction subscale is 'Being able to keep busy all the time'. Where as the example of the item in extrinsic job satisfaction subscale is "The way my boss handles his/her workers'. A total of 20 items which is rated on a five-point scale that range from $1=$ very dissatisfied to $5=$ very satisfied to response the perception on the satisfaction of the respondents' recent job. Higher scores indicate higher job satisfaction The reliability of the scale in this study was 0.93 which considered performing a high internal consistency for all the subscales.

Family Functioning was measured by Family Adaptability and Cohesion Evaluation Scale III (FACE-III) (Olson, 1993). A total of 20 items make up the FACE-III where 10 items described the family adaptability subscale and another 10 items described the family cohesion. Respondents were asked to answer the question on a Likert scale from $1=$ almost never to $5=$ almost always. Some of the items included were 'In solving problem, the children's suggestions are followed' and 'Family members ask each other for help'. Higher scores indicate higher level of adaptability and cohesion of the family. The Cronbach's alpha for FACE-III in this study was 0.80 .

\section{Data Analysis}

Foremost, a descriptive analysis was conducted to provide a clearer picture of the data distribution. Second, the magnitude and strength of the relationships of the study variables were quantitatively measured by Pearson Correlation. Later on, the mean score of two different groups were measured using t-test analysis. 
Table 1: Respondent's socio-demographical characteristics $(\mathrm{N}=180)$

\begin{tabular}{|c|c|c|c|c|c|c|}
\hline \multirow[b]{2}{*}{ Variables } & \multicolumn{2}{|c|}{ Overall $(\mathrm{N}=180)$} & \multicolumn{2}{|c|}{ Husband $(\mathrm{N}=90)$} & \multicolumn{2}{|c|}{ Wife $(\mathrm{N}=90)$} \\
\hline & $\mathrm{n}$ & $\%$ & $\mathrm{n}$ & $\%$ & $\mathrm{n}$ & $\%$ \\
\hline \multicolumn{7}{|l|}{$\overline{\text { Age }}$} \\
\hline$<28$ & 55.00 & 30.6 & 23.00 & 25.6 & 32.00 & 35.6 \\
\hline $28-33$ & 66.00 & 36.7 & 32.00 & 35.6 & 34.00 & 37.6 \\
\hline$>33$ & 59.00 & 32.8 & 35.00 & 38.9 & 24.00 & 26.7 \\
\hline$M$ & 32.15 & & 32.98 & & 31.32 & \\
\hline$S D$ & 5.95 & & 6.26 & & 5.53 & \\
\hline Min & 24.00 & & 24.00 & & 24.00 & \\
\hline Max & 56.00 & & 56.00 & & 55.00 & \\
\hline \multicolumn{7}{|l|}{ Years of Marriage } \\
\hline$<2$ & 54.00 & 30.0 & 27.00 & 30.0 & 27.00 & 30.0 \\
\hline 7-Feb & 66.00 & 36.7 & 33.00 & 36.7 & 33.00 & 36.7 \\
\hline$>7$ & 60.00 & 33.3 & 30.00 & 33.3 & 30.00 & 33.3 \\
\hline$M$ & 6.74 & & 6.74 & & 6.74 & \\
\hline$S D$ & 6.09 & & 6.11 & & 6.11 & \\
\hline Min & 1.00 & & 1.00 & & 1.00 & \\
\hline $\operatorname{Max}$ & 31.00 & & 31.00 & & 31.00 & \\
\hline \multicolumn{7}{|l|}{ Occupation Sector } \\
\hline Work for government & 135.00 & 75.0 & 58.00 & 64.4 & 77.00 & 85.6 \\
\hline Work for private company & 34.00 & 18.9 & 26.00 & 28.9 & 8.00 & 8.9 \\
\hline Own business & 7.00 & 3.9 & 5.00 & 5.6 & 2.00 & 2.2 \\
\hline Others & 4.00 & 2.2 & 1.00 & 1.1 & 3.00 & 3.3 \\
\hline \multicolumn{7}{|l|}{ Years of Education } \\
\hline$>15$ & 79.00 & 43.9 & 41.00 & 45.6 & 38.00 & 42.2 \\
\hline $15-17$ & 84.00 & 46.7 & 43.00 & 47.8 & 41.00 & 45.6 \\
\hline$>17$ & 17.00 & 9.4 & 6.00 & 6.7 & 11.00 & 12.2 \\
\hline$M$ & 15.71 & & 15.46 & & 15.97 & \\
\hline$S D$ & 2.13 & & 2.25 & & 1.99 & \\
\hline Min & 10.00 & & 10.00 & & 12.00 & \\
\hline Max & 20.00 & & 19.00 & & 20.00 & \\
\hline \multicolumn{7}{|l|}{ Total Monthly Income } \\
\hline$<\mathrm{RM} 2500.00$ & 2.00 & 1.1 & 23.00 & 25.6 & 34.00 & 37.8 \\
\hline RM2500.00-RM3500.00 & 12.00 & 6.7 & 36.00 & 40.0 & 36.00 & 40.0 \\
\hline$>$ RM3500.00 & 166.00 & 92.2 & 31.00 & 34.4 & 20.00 & 22.2 \\
\hline$M$ & 6792.56 & & 3755.29 & & 3075.05 & \\
\hline$S D$ & 3374.50 & & 2369.45 & & 1545.13 & \\
\hline Min & 2300.00 & & 1300.00 & & 1000.00 & \\
\hline Max & 23500.00 & & 15000.00 & & 10400.00 & \\
\hline
\end{tabular}

Note: $M=$ Mean, $S D=$ Standard Deviation, Min = Minimum, Max = Maximum

\section{Results}

\section{Personal Characteristics}

Results in Table 1 showed that about $36.7 \%$ of the respondents were age in the range between 28-33 years old. More over, most of the respondent were married between 2 and 7 years. Further, most of them (75\%) are working in goverment sector. Almost half of the respondents $(46.7 \%)$ had complete 15-17 years of education. Lastly, about $40.0 \%$ of respondents for both husband and wife had monthly income within RM2500.00-RM3500.

\section{Commuter Family Context}

Table 2 showed that most of the respondents (41.1\%) have been in the commuter family life in the range of 11-
36 months $(\mathrm{M}=30.42, \mathrm{SD}=31.93)$. The average travelling cost for husbands from work place to home was RM426.84 per month.

\section{Relationships between Job Satisfaction and Family} Functioning of Dual-Earner Commuter Family

Correlational analysis was utilized to explore the relationships among the study variables in the study (Table 3). The results show that job satisfaction was significantly correlated with overall family functioning $(r=0.18, p<0.05)$. The study indicate that high level of job satisfaction will increase the level of family functioning. However, only one out of two sub-scale of family functioning was found to significantly correlate with job satisfaction and it was cohesion $(r=0.32, p<0.01)$. 
Table 2: Commuter family contexts $(\mathrm{N}=90)$

\begin{tabular}{lrr}
\hline Commuter family context & $\mathrm{n}$ & $\%$ \\
\hline $\begin{array}{l}\text { Duration of Being Commuter Family } \\
<11 \text { months }\end{array}$ & & 31.10 \\
$11-36$ months & 28.00 & 41.10 \\
$>36$ months & 37.00 & 27.80 \\
$M$ & 25.00 & 31.93 \\
SD & 30.42 & \\
Costs of Travel Home Per Month & & 28.90 \\
<RM 250 & 26.00 & 37.80 \\
RM 250-RM 450 & 34.00 & 33.30 \\
$M$ RM 450 & 30.00 & 327.72 \\
SD & 426.84 &
\end{tabular}

Note: $M=$ Mean, $S D=$ Standard Deviation

Table 3: Correlation matric of study variables

\begin{tabular}{|c|c|c|c|c|c|c|}
\hline Variables & 1 & 2 & 3 & 4 & 5 & 6 \\
\hline 1. Job Satisfaction & 1 & & & & & \\
\hline 2. Intrinsic & $0.97 * *$ & 1 & & & & \\
\hline 3. Extrinsic & $0.93 * *$ & $0.82 * *$ & 1 & & & \\
\hline 4. Overall Family Functioning & $0.18^{*}$ & $0.18 *$ & $0.16^{*}$ & 1 & & \\
\hline 5. Cohesion & $0.32 * *$ & $0.29 * *$ & $0.32 * *$ & $0.76^{* *}$ & 1 & \\
\hline 6. Adaptation & -0.01 & 0.01 & -0.04 & $0.83 * *$ & $0.26 * *$ & 1 \\
\hline
\end{tabular}

Note: $* \mathrm{p}<0.05, * * \mathrm{p}<0.01$

Table 4: Differences in perception of job satisfaction and family functioning between husband and wife of dual-earner commuter family

\begin{tabular}{lllll}
\hline Variables & Husband $M(S D)$ & Wife $M(S D)$ & $\mathrm{t}$ & $\mathrm{p}$ \\
\hline Job Satisfaction & $67.14(11.28)$ & $64.97(10.49)$ & 1.34 & 0.18 \\
Intrinsic & $42.31(7.22)$ & $41.13(6.69)$ & 1.51 & 0.26 \\
Extrinsic & $24.83(4.61)$ & $23.83(4.27)$ & & \\
Overall family & & & -1.18 & \\
Functioning & $64.06(9.12)$ & $65.58(8.11)$ & -0.83 & 0.24 \\
Cohesion & $36.87(5.48)$ & $37.49(4.59)$ & -1.04 & 0.41 \\
Adaptation & $27.19(5.95)$ & $28.09(5.64)$ & 0.29 \\
\hline
\end{tabular}

Note: $M=$ Mean, $S D=$ Standard Deviation

Differences in Perception of Job Satisfaction and Family Functioning Between Husband and Wife of Dual-Earner Commuter Family

The aim of t-test analysis is to compare the mean score of two different groups (husband and wife) in perception of job satisfaction and family functioning. Analysis of t-test for all variables included in this study was presented in Table 4 . The results showed that there were no significant differences between husband and wife in job satisfaction and family functioning. The finding illustrated that husband and wife in this study had same level of perception towards job satisfaction and family functioning. As for the sub-scales of the family functioning, showed the same results between husband and wife in dual-earner commuter family.

\section{Discussion and Conclusion}

The current study was aimed to determine the relationships between job satisfaction and family functioning of dual-earner commuter family in Malaysia. The result of the pearson product-moment correlation coefficient between job satisfaction were significantly correlated with overall family functioning and cohesion dimension. The result of this study are in concordance with the previous study by Sanz-Vergel and RodriguezMunoz (2013), they found employee daily work positive experience and job satisfaction may transferred directly to home domain which contributed to increase the functioning of the family. Similarly to Viry et al. (2010) reported that mobility arrangement is the best possible compromise to find a balance between occupational absence and family cohesion, thereby leading to positive conjugal quality and family functioning in the dualearner commuter family.

Moreover, based on the finding indicates that there were no significant differences between husband and wife in job satisfaction and family functioning. This means that husband and wife in this study had a same level of perception towards job satisfaction and family 
functioning. Contrary to the previous research which showed that job satisfaction has a positive effect for men and slightly reduced for women (Roberts et al., 2011).

Overall, this finding in the current study will bring new information for researcher, community and especially the individual in the commuter families. According to Bergen (2010), findings on commuter research are potentially useful to commuter wives, their spouses, families, social network members, counsellors and therapists who work with commuting spouses.

The findings of the present study has implications for both husband and wife of dual-earner commuter family, practitioners, policy makers, government and nongovernment organization. The findings can be used by authorities such as Ministry of Women, Family and Community Development in Malaysia and nongovernmental organizations by make an improvement on the current practice. There is a need to make an early intervention and prevention programs at the work and family level in order to lessen the risk factor impact towards their job satisfaction and family functioning

Additionally, it is also hoped that the findings of this study can also help to improve and highlight the issues regarding workers that commute far from their family. Thus, this finding can be used by government and any institutions in Malaysia to formulate work family-friendly environtment (Lau et al., 2012) and social policies in order to facilitated high work involvement and also to maintain work family balance between men and women employee by reduced the working hours and give time off towerds commute spouse in order to participate intensively in their family activities when the commuter was home (Landesman and Seward, 2013).

There are several limitation to the current study that should be noted. Firstly, because of small sample size and the presented study only focused on Malay couples that comes from dual-earner commuter families. Thus, the limited of demographic homogenity will limit the generalizability. So, future studies are recommend to replicate more heterogeneous population that include others ethnic groups, social status and different family structure. Futurre studies are also recommend to use sructural equation modelling in analyzing the causal realtionship between the variables of the study. Lastly, this current study only focused on two aspects of dualearner commuter family (i.e. job satisfaction and family functioning). Therefore, it could be interesting if others aspects of dual-earner commuter family outcome were also employed in the future studies.

\section{Acknowledgement}

This research is under project entitled "Development a Model of Strengths and Stressors of Dual Earner
Commuter Family". Financial support from Fundamental Research Grant Scheme (FRGS) (Project code: 05-0213-11263R) of Ministry of Higher Education Malaysia was duly acknowledged.

\section{Author's Contributions}

All authors equally contributed in this work.

\section{Ethics}

There are no foreseeable ethical issues that may arise from the publication of this manuscript.

\section{References}

Alegre, I., M. Mas-Machuca and J. Berbegal-Mirabent, 2016. Antecedents of employee job satisfaction: Do they matter? J. Bus. Res., 69: 1390-1395.

DOI: 10.1016/j.jbusres.2015.10.113

Bergen, K.M., 2010. Negotiating a 'questionable' identity: Commuter wives and social networks. Southern Commun. J., 75: 35-56.

DOI: $10.1080 / 10417940902951816$

Fiori, M., G. Bollmann and J. Rossier, 2015. Exploring the path through which career adaptability increases job satisfaction and lowers job stress: The role of affect. J. Vocat. Behav., 91: 113-121.

DOI: $10.1016 /$ j.jvb.2015.08.010

Gagne, M. and E.L. Deci, 2005. Self determination theory and work motivation. J. Organiz. Behav., 26: 331-362. DOI: 10.1002/job.322

Ganzach, Y. and I. Fried, 2012. The role of intelligence in the formation of well-being: From job rewards to job satisfaction. Intelligence, 40: 333-342.

DOI: 10.1016/j.intell.2012.03.004

Glotzer, R. and A.C. Federlein, 2007. Miles that bind: Commuter marriage and family strengths. Michigan Family Rev., 12: 7-31.

DOI: $10.3998 / \mathrm{mfr} .4919087 .0012 .102$

Landesman, J. and R.R. Seward, 2013. Long distance commuting and couple satisfaction in Israel and United States: An exploratory study. J. Comparative Family Stud., 44: 765-781.

Lau, Y.K., J.L.C. Ma, P.S. Wan, T.K.T. Wong and L.Y. Lai, 2012. Work-family conflicts, family leisure activities and family functioning in Hong Kong. Proceeding of 18th Biennial International Employment Relation Association Conference, Jun. 26-28, Singapore, pp: 82-100.

Olson, D., 1993. Circumplex Model of Marital and Family System: Assessing Family System. In: Normal Family Processes, Walsh, F. (Ed.), Guilford Press, New York, pp: 104-137. 
Rabe, M.E., 2001. Commuter couples: An inside stories. Society Transit., 32: 277-291.

DOI: $10.1080 / 21528586.2001 .10419047$

Roberts, J., R. Hodgson and P. Dolan, 2011. 'It's driving her mad": Gender differences in the effects of commuting on psychological health. J. Health Econom., 30: 1064-1076.

DOI: $10.1016 /$ j.jhealeco.2011.07.006

Rotter, J.C., D.E. Barnett and M.L. Fawcett, 1998. On the road again: Dual-career commuter relationships. Family J., 6: 46-48.

DOI: $10.1177 / 1066480798061009$

Rupert, P.A., E.R.T. Hartman and A.S.O. Miller, 2013. Work demand and resources, work-family conflict and family functioning among practicing psychologist. Professional Psychol. Res. Pract., 44: 283-289.

Sanz-Vergel, A. and A. Rodríguez-Muñoz, 2013. The spillover and crossover of daily work enjoyment and wellbeing: A diary study among working couples. Revista de Psicología del Trabajo y de las Organizaciones, 29: 179-185.

DOI: $10.5093 / \operatorname{tr} 2013 \mathrm{a} 24$
Van der Klis, M., 2008. Continuity and change in commuter partnerships: Avoiding or postponing family migration. GeoJournal, 71: 233-247. DOI: $10.1007 / \mathrm{s} 10708-008-9159-3$

Viry, G., E.D. Widmer and V. Kaufman, 2010. Does it matter for us that my partner or I commute? J. Family Res., 22: 149-170.

Weiss, D.J., R.V. Dawis, G.W. England and L.H. Lofquist, 1967. Manual for the Minnesota Satisfaction Questionnaire. 1st Edn., University of Minnesota, Minneapolis, pp: 120.

Zubrick, S., A.A. Williams, S.R. Silburn and G. Vimpani, 2000. Indicators of Social and Family Functioning. Department of Family and Community Services, Common-Wealth of Australia, Canberra. 